\title{
At what age could screening for familial retinoblastoma be stopped? A register based study 1945-98
}

Annette C Moll, Saskia M Imhof, Antoinette Y N Schouten-Van Meeteren, Maarten Boers

\begin{abstract}
Aim-To evaluate until what age children in families with retinoblastoma should be screened.

Methods-A register based cohort (n= 685) study of Dutch retinoblastoma patients (1945-1998). The records of all familial hereditary retinoblastoma patients from 1945 were reviewed and the age at diagnosis and either they were screened from birth determined.

Results-75 patients had the familial hereditary form of retinoblastoma. The mean age at diagnosis in patients with fundus screening $(n=50)$ from birth on was 4.9 months (median 1.9 months; range 1 day to 48 months). Thus, 4 years was the latest onset of familial retinoblastoma properly evaluated from birth. This mean age was significantly different $(p<0.0001)$ from the mean age at diagnosis in patients without fundus screening $(n=25)$ from birth (mean 17.2 months; median 10.0 months; range 1.5-63.0 months).

Conclusions-Ophthalmological screening of children and sibs at risk for familial hereditary retinoblastoma is recommended until the age of 4 years in order to detect retinoblastoma as early as possible. (Brf Ophthalmol 2000;84:1170-1172)
\end{abstract}

Department of Ophthalmology, Vrije

Universiteit, Amsterdam, Netherlands A C Moll

$S \mathrm{M}$ Imhof

Department of Pediatrics A Y N Schouten-Van Meeteren

Department of Clinical Epidemiology and Biostatistics

A C Moll

$M$ Boers

Correspondence to: Dr Annette C Moll, Department of Ophthalmology, Academic Hospital, Vrije Universiteit, De Boelelaan 1117, 1081 HV Amsterdam, Netherlands a.moll@azvu.nl

Accepted for publication 25 April 2000
Retinoblastoma, the most common ocular malignancy in children, results from malignant transformation of primitive retinal cells before final differentiation. These primitive cells disappear within the first years of life, so retinoblastoma seldom develops at an older age. Retinoblastoma is diagnosed at an average age of 18 months, with the bilateral cases being recognised at an average age of about 12 months and the unilateral cases at 23 months. In rare instances, the tumour is first recognised at birth, in the teens, or even in adulthood. ${ }^{1-3}$

The disease exhibits a hereditary and a nonhereditary occurrence. In $40 \%$ of all children with retinoblastoma there is a heritable tendency to develop tumours. In this group, the primitive retinal cells are predisposed to malignant transformation by a germline mutation that is highly penetrant $(90 \%)$ and shows a pattern of autosomal dominant transmission. A child born to a parent with the germinal form of retinoblastoma has a $45 \%$ chance of developing retinoblastoma. These patients are usually detected by having bilateral, multiple tumours. However, $15 \%$ of unilateral cases are also heritable. ${ }^{4}$ Sibs of patients with bilateral or unilateral retinoblastoma have a risk of $3 \%$ and $0.5 \%$, respectively, to have retinoblastoma. ${ }^{5}$ Ten per cent ${ }^{6}$ of all patients with retinoblastoma have a positive family history for retinoblastoma.

Precise genetic counselling will be possible only when the retinoblastoma mutation can be detected in the family. If the retinoblastoma gene mutation is not found children and sibs born into a family with retinoblastoma are frequently examined first at birth and then within weeks in an attempt to diagnose the tumour as early as possible. In the past it was customary to continue such examinations until the age of 7 years, in the Netherlands. Currently this age is 4 years. If the inheritance aspect of retinoblastoma is not clear to the parents, some children with the familial hereditary form of retinoblastoma are not ophthalmologically screened from birth.

The aim of this study was to determine at what age screening for familial retinoblastoma can be stopped. Therefore, were evaluated patients with a positive family history for retinoblastoma with respect to the age at diagnosis and the relation with ophthalmological examinations from birth. The study question was: is ophthalmological screening of children and sibs at risk for retinoblastoma until the age of 4 years safe? Is it either possible to screen for less time or necessary to screen longer?

\section{Patients and methods}

The Dutch Retinoblastoma Register (18621998) was updated as described in previous reports ${ }^{7}$ and contained 991 patients. Fifty two families were detected and 94 patients had a positive family history. A retinoblastoma family is defined as two or more related family members with retinoblastoma. The "first" family member is regarded as sporadic hereditary retinoblastoma. The second and next family members are regarded as familial hereditary retinoblastoma. The following characteristics were obtained: date of birth, the age of diagnosis of retinoblastoma in months, laterality of the tumour, sex, relation with oldest patient in the family, and the method of diagnosis (screening from birth or not). Familial hereditary retinoblastoma patients born before 1945 $(n=19)$ were excluded because the age at diagnosis of retinoblastoma was not always available.

The statistical analyses were performed with STATVIEW (SAS, 1992-8). The Mann-Whitney U test was used for non-parametric data to 


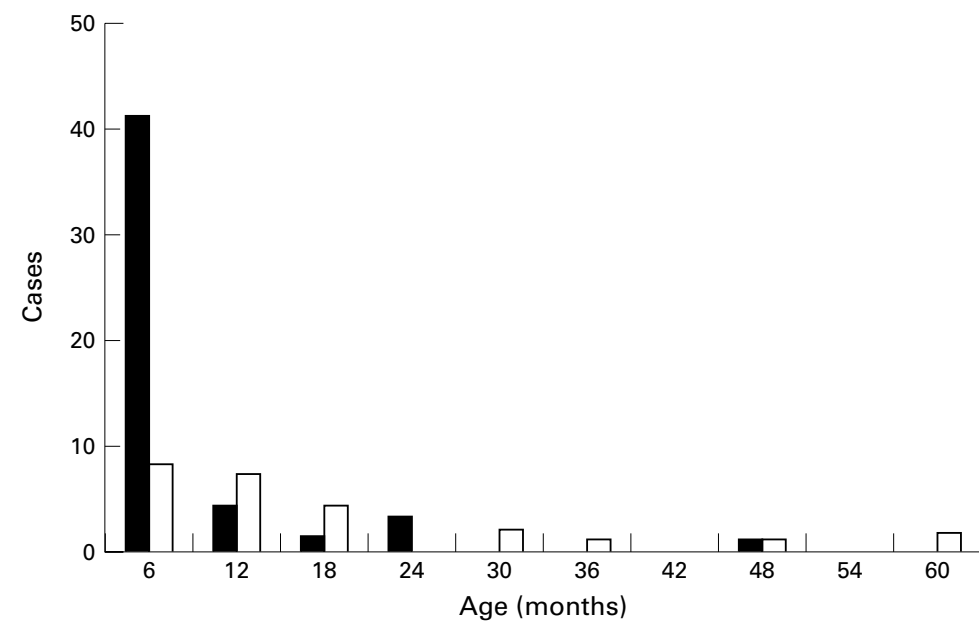

Figure 1 Age at diagnosis (months) in familiar hereditary retinoblastoma with ( $n=50)$ (solid bars) and without $(n=25)$ (open bars) fundus screening from birth.

Table 1 Overview of the literature of the age at diagnosis of familial retinoblastoma

\begin{tabular}{|c|c|c|c|c|c|c|}
\hline \multirow[b]{2}{*}{ Article } & \multirow[b]{2}{*}{$n=$} & \multirow[b]{2}{*}{ Years } & \multicolumn{4}{|c|}{ Age at diagnosis (months) } \\
\hline & & & Mean & Median & Range & \\
\hline \multirow[t]{2}{*}{ Matsunaga, $1976^{8}$} & 30 & ? & 10.2 & ? & $0-39$ & \multirow{6}{*}{$\begin{array}{l}\text { bilateral } \\
\text { unilateral } \\
\text { bilateral } \\
\text { unilatera }\end{array}$} \\
\hline & 19 & ? & 19.0 & ? & $?-48$ & \\
\hline \multirow[t]{2}{*}{ Draper, $1992^{9}$} & 108 & $1962-1985$ & 7.2 & 5 & $0-47$ & \\
\hline & 41 & $1962-1985$ & 20.3 & 15 & $0-119$ & \\
\hline Abramson, $1998^{\star 10}$ & 21 & $1960-1990$ & $?$ & 5.5 & $1-28$ & \\
\hline Moll, 1999^ & 50 & $1945-1998$ & 4.9 & 1.9 & $0-48$ & \\
\hline
\end{tabular}

$\mathrm{n}=$ number of familial patients; *only patients screened from birth.

compare the age at diagnosis of retinoblastoma in the ophthalmologically screened and nonscreened patient group.

\section{Results}

The Dutch Retinoblastoma Register is virtually complete from 1945 and contained 685 retinoblastoma patients born between 1945 and 1998. Forty seven retinoblastoma families were found with patients born after 1945. Five other families had only family members born before 1945 and no descendants born after 1945. Of the 685 retinoblastoma patients 75 patients $(9.1 \%)$ had the familial hereditary form of retinoblastoma. Fifty patients were ophthalmologically screened from birth (67\%) and 25 patients were not screened from birth $(33 \%)$ as the hereditary aspect of retinoblastoma was not known to the parents. The mean age at diagnosis of retinoblastoma in familial hereditary retinoblastoma patients with fundus screening from birth $(n=50)$ was 4.9 months (median 1.9 months; range 1 day to 48 months). This was significantly lower $(\mathrm{p}<0.0001)$ than the mean age $(17.2$ months $)$ at diagnosis of familial hereditary retinoblastoma in patients without fundus screening (median 10.0 months; range 1.5-63.0 months) (Fig 1).

Twenty two $(44 \%)$ of the tumours in the screened group $(n=50)$ were seen at the first visit to the ophthalmologist. Fifty per cent of the first tumours were seen before the age of 2 months. In only two patients were the new tumours seen at the age of 24 months. The next and final first newly identified tumour in a patient was at 48 months.
Twelve (16\%) of the 75 familial retinoblastoma patients were unilaterally affected, in six cases it was in the right eye and in six cases the left eye. Sixty three of the 75 patients $(84 \%)$ were bilaterally affected. Thirty one (41\%) boys and 44 girls (59\%) were found with the familial hereditary form. Of the 75 patients, 35 were a daughter of the oldest patient in the retinoblastoma family, 21 a son, four a sister, two a brother, five a granddaughter, three a grandson, one a niece, and four a nephew.

\section{Discussion}

The age at diagnosis of familial retinoblastoma has been described by other authors (Table 1). ${ }^{8-10}$ In the series of Abramson ${ }^{10}$ the oldest patient screened from birth with familial retinoblastoma was 28 months. The other authors did not take into account the age at diagnosis in case of screening from birth. Abramson's group published several articles regarding age at onset of the different hereditary and non-hereditary forms of retinoblastoma of the same patient group in New York. His most recent article $^{10}$ regarding the familial form of retinoblastoma is given in Table 1 . Their retrospective analysis of 358 cases of retinoblastoma for correlation between age and intraocular stage at time of diagnosis revealed that the existence of a positive family history for retinoblastoma does not guarantee an earlier age at diagnosis compared with sporadic disease. ${ }^{11}$ Furthermore, they found that only in the very young age group (0-3 months) were most of the tumours found in the early ReeseEllsworth stage I-III. For most other ages at detection, the same number or more patients with advanced disease (RE stage $\mathrm{V}$ ) were found than those with early stage disease.${ }^{11}$ In an article on only parents with the unilateral form of hereditary retinoblastoma the mean age at diagnosis of their affected children was 10.5 months (range 1-36 months). The conclusion was that the characteristics of retinoblastoma patients with a unilaterally affected parent were similar when compared with all retinoblastoma patients with a positive family history. ${ }^{12}$

In the Netherlands, especially in older generations, not all offspring and sibs from retinoblastoma patients underwent ophthalmological examinations from birth. As also described by Shields ${ }^{13}$ some parents may be reluctant to inform the child that he or she had cancer during infancy and may even lead him or her to believe that the eye was removed because of trauma of infection. The patient may grow up and have children without realising that there is a possibility of transmitting a malignant tumour to them. But also some ophthalmologists did not inform the parents or patients regarding the possible hereditary aspect of the disease, especially in case of unilateral retinoblastoma. DerKinderen ${ }^{14}$ described that in his series (patients born between 1945 and 1970) 28 of the 87 cases with bilateral retinoblastoma without affected relatives the recurrence risk of the disease was unknown to the family.

Musarella and Gallie ${ }^{5}$ recommend complete retinal examination for offspring, twins and 
siblings of retinoblastoma patients: at birth and monthly without anaesthetic until 3 months of age, examination under anaesthetic every 2 months to age 7 months, every 3 months to age 18 months, and every 6 months to age 3 years. Subsequently (semi)annual clinical examination is advisable depending on the risk for retinoblastoma. Abramson et $a l^{10}$ discussed dilated ophthalmic examinations as often as $2-4$ weeks during the first 6 or 12 months of life (necessitating anaesthesia for most of the examinations). He stated that ophthalmic examinations are appropriate for the first 28 months of life. Our recommendation includes examination without anaesthetic from birth to age 3 months every 2 or 4 weeks. After age 3 months examination under anaesthetic is warranted every 2 months until age 1 year. In the second year of life every 3 months, in the third year of life every 4 months, and in the fourth year every 6 months. Anaesthesia is necessary up to 3 years of age since attention must be given to locations anterior and posterior to the equator and even to the ora serrata.

Predictive testing to detect retinoblastoma gene mutations using molecular analysis is an integral part of contemporary retinoblastoma management. Accurate carrier risk assessment depends on direct identification of the causative RB1 mutation. Mutation analysis can now be offered to an increased number of individuals. ${ }^{15}$ Even constitutional RB1 gene mutations are found in patients with isolated unilateral retinoblastoma. ${ }^{16}$ But molecular analysis is not always informative; therefore in case of a negative finding in molecular analysis it is impossible to detect carriers in offspring or siblings and funduscopy from birth is necessary. The problems of the RB1 gene being very large is discussed in a meta-analysis of Harbour. ${ }^{17}$ Owing to its length, mutations can occur throughout the gene with no single hotspot and the available techniques for direct sequencing the gene are labour intensive and time consuming. But a cost comparison of molecular versus conventional screening of relatives at risk for retinoblastoma revealed a significant saving of healthcare dollars by the molecular route, indicating the benefit of redirecting economic resources to molecular diagnosis in retinoblastoma. The ethical issues of molecular diagnosis of the presence of an RB1 mutation in an infant seem relatively minor, since effective therapy is available to treat retinoblastoma tumours when they are discovered early, preventing blindness and death. ${ }^{18}$ For families and their children it is important to avoid stressful funduscopy under general anaesthesia if it is not necessary.

The results of this cohort study may be useful in the management of familial retinoblastoma. They could reduce the burden of examinations for children and their families, for the ophthalmologist, and the cost for the insurance companies. In conclusion, in the Netherlands, not all offspring and sibs from retinoblastoma patients underwent screening by ophthalmological examinations from birth. Funduscopy at least until the age of 2 years is recommended. Follow up until the age of 4 years provides optimum safety. Extended screening beyond this age is not necessary. In the future, detection of the retinoblastoma gene mutation of children at risk will probably displace screening by repeated ophthalmological examinations under general anaesthesia from birth.

1 Bishop JO, Madsen EC. Retinoblastoma: review of current status. Surv Ophthalmol 1975;342:342-66.

2 Shields CL, Shields JA, Shah P. Retinoblastoma in older children. Ophthalmology 1991;98:395-9.

3 Mietz H, Hutton WL, Font RL. Unilateral retinoblastoma in a adult. Report of a case and review of the literature. Ophthalmology 1997;104:43-7.

4 Vogel F. Genetics of retinoblastoma. Hum Genet 1979;52:154

5 Musarella MA, Gallie BL. A simplified scheme for genetic counseling in retinoblastoma. F Pediatr Ophthalmol 1987; 24:124-5.

6 Moll AC, Imhof SM, Bouter LM, et al. Incidence and survival of retinoblastoma in the Netherlands: a register-

based study 1862-1995. Br f Ophthalmol 1997;81:559-62.

7 Moll AC, Imhof SM, Koten JW, et al. Second primary umors in patients with hereditary retinoblastoma: a registered-based follow-up study 1945-1994. Int f Cancer 1996;67:515-19.

8 Matsunaga E. Hereditary retinoblastoma: penetrance, expressivity and age of onset. Hum Genet 1976;33:1-15.

9 Draper GJ, Sanders BM, Brownbill PA, et al. Patterns of risk of hereditary retinoblastoma and applications to genetic counselling. Br f Cancer 1992;66:211-19.

10 Abramson DH, Mendelsohn ME, Servodidio CA, et al. Familial retinoblastoma: where and when? Acta Ophthalmol Scand 1998;76:334-8.

11 Rubenfeld M, Abramson DH, Ellsworth RM, et al. Unilateral vs bilateral retinoblastoma. Correlations between age at diagnosis and stage of ocular disease. Ophthalmol 1986;93:1016-19.

12 Notis CM, Niksarli K, Abramson DH, et al. Parents with unilateral retinoblastoma: their affected children. $\mathrm{Br} \mathcal{F} \mathrm{Oph}$ thalmol 1996; 80:197-9.

13 Shields JA, Shields CL. Genetics of retinoblastoma. In: Shields JA, Shields CL, eds. Intraocular tumors. A text and atlas. Philadelphia: Saunders, 1992:333-40.

14 DerKinderen DJ. A new concept of oncogenesis with an evaluation in retinoblastoma. Thesis, Utrecht 1987.

15 Lohmann DR, Brandt B, Oehlschlager U, et al. Molecular analysis and predictive testing in retinoblastoma. Ophthalmic Genet 1995;16:135-42.

16 Lohmann DR, Gerick M, Brandt B, et al. Constitutional RB1-gene mutations in patients with isolated unilateral retinoblastoma. Am f Hum Genet 1997;61:282-94.

17 Harbour JW. Overview of RB gene mutations in patients with retinoblastoma. Implications for clinical genetic screening. Ophthalmol 1998;105:1442-7.

18 Noorani HZ, Khan HN, Gallie BL, et al. Cost comparison of molecular versus conventional screening of relatives at risk for retinoblastoma. Am F Hum Genet 1996;59:301-7. 